\title{
Reformar para retardar A lógica da mudança no EM
}

JAqueline MolL

RESUMO: Além de reflexões acerca dos condicionantes estruturais que conformam historicamente a educação brasileira como locus de seleção social, o texto aponta o caminho, na última década, na contramão desses condicionantes, com ações governamentais e marcos legais, tendo como referência a Emenda Constitucional n59/2009 (obrigatoriedade do ensino médio), no alargamento dos anos de obrigatoriedade da educação básica. Há diferentes aspectos da chamada reforma reveladores da restauração conservadora em curso no cenário político, cultural, econômico, social e educacional do Brasil pós-impeachment.

\section{Reforming to go backwards}

The logic of change in MS

\begin{abstract}
In addition to reflections on the structural constraints that historically make up Brazilian education as a locus of social selection, the text demonstrates how we have moved away from dealing with these constraints, over the last decade, due to governmental actions and legal frameworks, which use Constitutional Amendment No. 59 / 2009 as their reference (compulsory secondary education), in extending the number of compulsory years of basic education. There are different aspects of these so-called reforms as a result of the conservative restoration underway in Brazil's post-impeachment political, cultural, economic, social, and educational scenario.
\end{abstract}

* É doutora em Educação pela Universidade Federal do Rio Grande do Sul e professora titular da Faculdade de Educação da Universidade Federal do Rio Grande do Sul. É conselheira do Conselho Estadual de Educação do Rio Grande do Sul. Porto Alegre/RS - Brasil. E-mail: <jaquelinemoll@gmail.com>. 


\section{Reformar para atrasar \\ La lógica del cambio en la enseñanza media}

RESUMEN: Además de reflexiones sobre los factores condicionantes estructurales que conforman históricamente la educación brasileña como locus de selección social, el texto señala el camino, en la última década, en dirección contraria a esos condicionantes, con acciones gubernamentales y marcos legales, tomando como referencia la Enmienda Constitucional no 59/2009 (obligatoriedad de la enseñanza media), en la extensión de los años de obligatoriedad de la educación básica. Hay diferentes aspectos de la llamada reforma que revelan la restauración conservadora en curso en el escenario político, cultural, económico, social y educativo de Brasil tras el impeachment.

\section{Réformer para retarder}

\section{La logique du changement dans l'enseignement secondaire}

RÉSUMÉ: Au-delà des réflexions sur les conditions structurelles qui font historiquement de l'éducation brésilienne le lieu de la sélection sociale, le texte indique le chemin, lors de la dernière décennie, pris contre ces conditions, avec des actions gouvernementales et des repères légaux, comme l'Amandement Constitutionnel nº59/2009 (enseignement secondaire obligatoire), dans l'élargissement des années d'éducation de base obligatoires. Il existe différents aspects de la dite réforme qui sont révélateurs du retour au conservatisme en cours dans le scénario politique, culturel, économique, social et éducatif du Brésil post-destitution.

\section{Introduzindo o debate}

$\mathrm{N}$ o passado recente do Brasil, em que instituíram-se novos direitos educativos, como a obrigatoriedade do ensino médio na faixa etária dos 15 aos 17 anos, a necessidade de mudanças nessa etapa finalizadora da educação básica apresentou-se de modo inequívoco.

Herdeiro da tradição dual, qual seja, de encaminhar os jovens para destinos desenhados a partir do berço, elemento caraterístico de uma sociedade de quase-castas, o ensino médio encarnou historicamente (como escola secundária ou como $2^{\circ}$ grau) a 
lógica da profissionalização para os jovens das camadas populares e a lógica propedêutica para os poucos destinados ao ensino superior. Essa lógica manteve-se, inclusive, no período do regime militar, apesar da determinação legal da universalização de um ensino médio profissionalizante, nunca efetivado, pela ausência de infraestrutura, pessoal docente qualificado e insumos na escolas.

A consciência do direito de todos ao ensino médio é, ainda, na sociedade brasileira, um evento recente e não incorporado, do mesmo modo como lento e tardio foi o processo de incorporação do direito ao ensino fundamental, tanto na sua etapa primária, quanto ginasial, ao longo de todo século XX. Em que pese a quase universalização do ensino fundamental nos últimos 20 anos, as elevadas taxas de retenção e evasão dos estudantes demonstram, entre outros fatores, o não apreço à presença das classes populares em processos estendidos de escolarização.

Entre os elementos determinantes para a expansão dos anos obrigatórios de escolaridade, evidencia-se, no Brasil, a relação entre o acesso à escolarização e às demandas do sistema produtivo, fator significativo relacionado a saberes laborais, que poderia compor a determinação constitucional do pleno desenvolvimento da pessoa, articuladamente a outros aspectos do desenvolvimento humano, visando a inserção digna, de todos e de cada um, na estrutura societária. Ocorre que as desqualificadas condições do sistema escolar, somadas a profundas desigualdades sociais, também impõem aos jovens brasileiros profundas desigualdades na realização dos percursos escolares, obstaculizando, muito mais do que possibilitando, processos de desenvolvimento pleno (que evidentemente não se podem esgotar no âmbito da ação escolar).

Centradas em um intectualismo estéril, no qual as áreas do conhecimento não conversam entre si e, muito menos, com o mundo da vida dos jovens e do País e focadas na realização de exames para avaliação do sistema e, sobretudo, para acesso ao ensino superior, as práticas escolares no ensino médio reiteram modelos pedagógicos anacrônicos e, efetivamente, legitimam a seleção social determinada historicamente por uma estrutura de matriz escravocrata.

Na última década foram abertas fendas neste desenho social, através de diferentes políticas públicas, entre as quais, a de redistribuição de renda e de acesso popular ao ensino superior, tanto através do sistema de cotas, como através da expansão de vagas públicas ou financiadas pelo poder público. Significativo número de jovens pobres constituíram os primeiros, em gerações e gerações de suas famílias, a concluir o ensino médio e a chegar no ensino superior.

Fendas que fomentaram fortes reações daqueles historicamente acostumados com um país, cujos donos sempre garantiram a seus filhos as melhores colocações, seja nas universidades, seja no mercado de trabalho, caracterizando um "modelo meritocrático" em que o esforço pessoal é quase que completamente substituído pelas garantias do berço e do sobrenome. Essas reações fomentaram, entre outros fatores, os movimentos 
que desencadearam, no ano de 2016, o impeachment de Dilma Rousseff, eleita para o segundo mandato na Presidência da República em 2014.

Sob o argumento da obsolescência do ensino médio brasileiro, revelada nos baixos índices de aproveitamento escolar dos estudantes, o Governo Federal, através do Ministério da Educação, propôs a medida provisória 746/2016, transformada na Lei 13.415/2017, que reforma o ensino médio.

As reflexões desse texto buscam contextualizar e compreender aspectos dessa reforma, desde a matriz histórica de organização e funcionamento do sistema educacional brasileiro, apresentar algumas ações relacionadas ao ensino médio, no âmbito do Governo Federal na última década, e pensar os caminhos para o ensino médio, desde as perspectivas de diferentes projetos de país e de desenvolvimento que os conformam. Toma por base a compreensão da educação como direito de cidadania, recorrendo a Hannah Arendt para quem cidadadania é direito a ter direitos e pressupõe igualdade, liberdade e a própria existência e dignidade humanas.

\section{Alguns aspectos do sistema escolar brasileiro}

O atropelamento dos processos legais e constitucionais, sempre sob o discurso da legalidade e da constitucionalidade, que caracterizou as rupturas da ordem democrática no Brasil, explicita o declínio de períodos históricos que Anísio Teixeira denominou como intervalos democráticos. Em outras palavras, nossa democracia está longe de constituir-se como percurso ascendente, baseado nos ideais de liberdade, igualdade e fraternidade. Nos caraterizamos como uma sociedade profundamente desigual, tecida a partir de lugares pétreos demarcados, metaforicamente, como casa-grande e senzala, partindo do pressuposto de que parte significativa da população não teve e não tem direito a ter direitos.

Os declínios e ocasos dos intervalos democráticos são, invariavelmente, precedidos por movimentos de afirmação de identidade nacional e de enfrentamento das mazelas que nos acompanham desde a chegada dos portugueses no século XVI, mazelas que podem ser traduzidas na exclusão da população originária (povos indígenas), dos negros (povos africanos escravizados) e dos mestiços, em relação ao que a "civilidade européia" institui como modo de vida advindo da metrópole para a colônia. O letramento e a escolarização, nos diferentes níveis, constituem-se eixos importantes da inclusão nesse modo de vida.

A similaridade do cenário que precede o atual momento da sociedade brasileira, com o das rupturas vividas em 1935 e em 1964 pode ser expressa nos movimentos e feitos de afirmação da educação como direito de todos, da significativa expansão do financiamento público e da constituição de oportunidades educativas nos diferentes níveis e etapas de ensino. 
A paralisia do atual Plano Nacional de Educação (PNE), transformado na lei 13.005/2014, organizado em 10 metas e inúmeras estratégias para execução no período 2014-2024, entre as quais a expansão do PIB a ser aplicado na área, é comparável com o congelamento do primeiro PNE, aprovado em 1962 e nunca executado, por força do arbítrio instalado no País em 1964. Do mesmo modo que as definições constitucionais de 1934 foram congeladas pelo Estado Novo e substituídas pelos preceitos autoritários de 1937 e congeladas, junto, foram as aspirações explicitadas no Manifesto dos Pioneiros da Educação Nova de 1932, que propunha uma educação primária universal, gratuita, obrigatória, laica e que juntasse nas mesmas classes meninos e meninas (a denominada co-educação). Nos anos 70, ainda tínhamos resquícios dessa segregação.

Portanto, feita de rupturas e planos não executados, a história da educação escolar no Brasil não pode ser entendida fora dos marcos da história política do País. A lentidão da expansão e da qualificação das redes públicas de ensino deve, portanto, ser compreendida pelas lentes de Darcy Ribeiro que se referia a crise da educação brasileira, não como uma crise, mas como um projeto. Projeto esse que sempre excluiu parcelas significativas da população, sequer conferindo-lhes a condição de humanidade.

Sob tais pressupostos, constituímos um sistema escolar tardio, seletivo e excludente, que se organizou de modo a naturalizar os processos de reprovação e evasão, como expressões próprias das dificuldades de um grupo social "não vocacionado" para os saberes acadêmicos.

Nessa perspectiva, o analfabetismo e os baixos níveis de escolaridade de significativas parcelas da população podem ser compreendidos como expressões estruturais de exclusão social e de marginalização econômica, trazendo profundas consequências para o campo dos direitos e, portanto, para a consolidação e a qualificação da democracia.

Diferentemente do ocorrido em diversos países ocidentais, o advento da República não significou, para o povo brasileiro, mudança significativa das condições de vida e de participação na esfera pública. Além de tardia, em relação a outras nações ocidentais, inclusive sul-americanas, como Chile, Argentina e Uruguai, a oferta de educação escolar pública caracterizou-se pela não-universalização, pois não estendia-se a todos e nem cobria todo território nacional, concentrando-se primeiramente nas regiões mais centrais das cidades e destinando-se às camadas mais altas da sociedade. Aliás, naqueles países, o processo de desenvolvimento caminhou par e passo com o processo de expansão da educação primária.

Em nosso país, esse sistema tardio, desigual e seletivo foi construindo respostas auto-justificadoras para explicar porque tantos iam sendo deixados pelo caminho, por sucessivas reprovações e/ou por saídas extemporâneas. $\mathrm{O}$ fracasso escolar era, e ainda é, atribuído a características biológicas, psicológicas e culturais das crianças e jovens, em geral provenientes de grupos sociais pobres e miseráveis, conforme estudos de Patto (1990). 
Produziram-se e consolidaram-se, então, na formação dos profissionais da educação e nas práticas e discursos escolares, processos que denomino como patologização da pobreza e naturalização do fracasso escolar (Moll, 1997, 2001).

Outra característica marcante de nosso sistema escolar foi, historicamente, a organização em turnos, o que impôs uma grande limitação aos processos de aprendizado, por requererem tempo de reflexões, diálogos, escutas e elaborações, sobretudo para estudantes oriundos de famílias com baixa ou nenhuma escolaridade. Assim, além das outras características do sistema educacional brasileiro, pode-se acrescentar seu "encurtamento", analisado em Leclerc e Moll (2012).

A esse quadro de "pouca escola", sucede-se a entrada prematura e precária no mundo do trabalho pelos filhos das classes populares, processo que será determinante para uma precarização duradoura ao longo da vida. A este respeito Anísio Teixeira assevera que a despeito da tremenda expansão do conhecimento humano, um paradoxal imediatismo escolar reduziu a duração dos cursos e do dia escolar a fim de oferecer a maior número de alunos uma educação primária reduzida ao mínimo. (2011, p. 125)

A fragilidade de nossos processos democráticos relaciona-se, estruturalmente, com o desafio da equidade de acesso e permanência ao sistema educacional, em seus diferentes níveis e etapas, incluindo-se o tema da ampliação do tempo escolar diário. Círculos viciosos compostos de trajetórias escolares desqualificadas e inconclusas, para milhões de brasileiros, alinham-se a outros elementos estruturais que mantêm a sociedade injusta que somos. Entre eles, a questão da distribuição de terra, do saneamento básico, do acesso a moradia, da qualidade do transporte, da saúde pública e das oportunidades de trabalho e geração de renda.

\section{Ensino médio: desafio estrutural e feitos recentes}

A oferta do ensino médio como etapa conclusiva da educação básica constitui-se expressivo desafio na realidade brasileira pelo conjunto dos elementos apontados. Na medida em que avança o nível de escolaridade e a idade dos estudantes, agrava-se a situação de exclusão escolar por razões relacionadas tanto a estrutura e organização interna do trabalho escolar, quanto pela inserção precoce e precária ao mundo do trabalho, na luta pela sobrevivência. $\mathrm{O}$ avanço na escolaridade está diretamente ligado às condições de vida da população e à execução de políticas públicas que garantam condições de acesso e permanência na escola.

Aponto como marco legal importante para o avanço do ensino médio no Brasil, apesar da morosidade na vida real, a configuração da educação básica apresentada pela Lei de Diretrizes e Bases da Educação Nacional (LDBEN) de 1996, na qual esse nível de ensino compôs sua fase conclusiva. O fato de somente em 2009, pela Emenda Constitucional (EC) 
59, ter sido estabelecida sua obrigatoriedade, só e especificamente para a faixa etária de 15 a 17 anos, atesta a lentidão do avanço dos direitos educativos no Brasil.

Em que pese a importância, nos oito anos de governo FHC (1995-2002), do foco nas políticas do ensino fundamental, a perspectiva de uma escolaridade básica estendida da educação infantil ao ensino médio, apresentada pela LDBEN, só ganha efetiva correspondência nas políticas educacionais do Governo Federal, especialmente no campo do financiamento, no período seguinte, nos governos Lula e parte dos governos Dilma.

Destaco como elementos a serem considerados na análise dos avanços que desembocaram na EC 59, a inclusão do ensino médio no Programa Nacional do Livro Didático (PNLD), no Programa Nacional de Alimentação Escolar (Pnae), no Programa Nacional de Transporte Escolar (PNTE) e, sobretudo, no Fundo de Manutenção e Desenvolvimento da Educação Básica e de Valorização dos Profissionais da Educação (Fundeb, 2007) - em substituição ao Fundo de Manutenção e Desenvolvimento do Ensino Fundamental e de Valorização do Magistério (Fundef, 1996).

A complementariedade de recursos financeiros e materiais da União aos estados representou significativo incremento nas políticas educacionais para o ensino médio.

Além disso, a revogação do Decreto 2.208/98 e a efetivação do Decreto 5.154/04 permitiu que se retomasse a perspectiva de um ensino médio que integrasse a formação humana geral a educação profissional.

Neste caminho, o Programa Brasil Profissionalizado (2007) propiciou aos estados da União, por processo de adesão, a reconstrução das condições de infraestrutura para oferta do ensino médio articulada à educação profissional.

A significativa expansão e reorganização da Rede Federal de Educação Profissional e Tecnológica também representaram importante avanço no desenho de um ensino médio qualificado, de tempo ampliado e de formação humana integral, dadas as condições de infraestrutura, qualificação e carreira docente dessas instituições.

Em torno de 2010 efetiva-se programa federal indutor de novas possibilidades pedagógicas e curriculares no ensino médio, o Ensino Médio Inovador (EMI), que configurou-se a partir da experiência do Programa Mais Educação, realizado no âmbito do ensino fundamental no período 2007-2014. O EMI estruturava-se a partir da oferta de macrocampos pedagógicos nas áreas de cultura e artes, esporte, comunicação e mídias, entre outras, que previam a adesão da escola e a realização de atividades complementares, a serem articuladas com os projetos em curso nas escolas de ensino médio. As ações do EMI apontavam para a ampliação tanto dos horizontes formativos, quanto do tempo diário na escola, no caminho de uma escola de tempo integral e de formação humana integral.

No contexto do Pacto de Fortalecimento do Ensino Médio, firmado com os estados no ano de 2013, o EMI ampliou seu alcance, atingindo número significativo de escolas e, sobretudo, ganhando novos sentidos nos processos de formação, desencadeados no âmbito de cada escola, sob a coordenação do MEC, das secretarias estaduais de Educação 
e das universidades públicas. O Pacto previa significativo número de ações, entre as quais a recuperação da infraestrutura das escolas, o avanço no acesso aos meios tecnológicos, o estímulo ao desenvolvimento do pensamento científico e do aprendizado de línguas estrangeiras, as bolsas para professores de ensino médio em processos de formação, entre outras ações.

O caminho que vinha sendo trilhado pressupunha o diálogo com as redes públicas e com as escolas, partido do princípio de que há, sim, muita vida inteligente na educação básica, materializada em experiências exitosas de configurações pedagógicas e curriculares do ensino médio.

Este breve resumo aponta para um conjunto de ações, ainda insuficientes, mas efetivamente postas em marcha, em um contexto de afirmação de direitos e de construção de relações democráticas, que ganhou no PNE 2014-2024 metas e estratégias específicas para consolidação do ensino médio como etapa conclusiva da educação básica.

\section{Reformar para retardar: aspectos da Lei 13.415/2017}

No contexto das mudanças políticas do ano de 2016, que desencadeou a deposição da presidente da República, a primeira das reformas propostas foi a do ensino médio. Considerando a composição do Governo Michel Temer, a retomada do controle do MEC por parte do grupo que acompanhou o ministro Paulo Renato Souza (1994-2002) pode, em certa medida, explicar a rapidez com que a Medida Provisória (MP) 746/2016 foi apresentada ao País. Uma resposta certeira à ousadia do grupo político deposto, que elevou o ensino médio à condição de obrigatoriedade a todos os jovens na faixa etária de 15 a 17 anos.

Impossível fazer a leitura dessa MP sem contextualizá-la no arcabouço da Emenda Constitucional que congelou os "gastos públicos" por 20 anos, do Projeto de Lei que prevê a escola com mordaça (cuja resposta negativa do Supremo Tribunal Federal já foi dada à lei congênere, aprovada na Assembléia Legislativa de Alagoas), das reformas em curso das leis trabalhistas e previdenciárias e da paralisia do PNE 2014-2014. Esse arcabouço é revelador da conjuntura histórica de restauração conservadora, que, encerrando mais um intervalo democrático, devolve os fins e meios do Estado brasileiro para o grupo social, politico e econômico que sempre o monopolizou.

O aumento significativo de recursos federais para a educação brasileira, no período 2003-2014, na ordem de 3\% para 6\% do Produto Interno Bruto, revela-se como importante elemento na disputa por um novo formato para a educação básica, vide os esforços realizados na direção da chamada Base Nacional Curricular Comum (BNCC), que exigirá novos livros e materiais didáticos, além de mudanças que arregimentarão a indústria da avaliação e do treinamento de professores. 
Essa disputa não é menos importante que a disputa sócio-ideológica por um modo de escola e de currículo que formate determinado tipo de sujeitos.

Ao ancorar toda mudança do ensino médio na BNCC, apesar de centralizar o currículo no ensino do Português, da Matemática e do Inglês, a reforma alimenta a ilusão de que o problema da educação básica no Brasil é o da definição de conteúdos curriculares.

Ora, um olhar raso sobre os resultados de aprendizagem dos estudantes matriculados em escolas dotadas de condições de infraestrutura, valorização docente, e com riqueza curricular e tempos alargados de aprendizagem - como os institutos federais e as escolas vinculadas a universidades federais, Colégio Pedro II, escolas estaduais que oferecem ensino médio integrado, escolas do Sesi ou Sesc - demonstra que o recorte específico dos saberes a serem ensinados não é elemento garantidor da qualidade desejada, mas a consequência de projetos educacionais densos, contínuos e qualificados.

A ilusão cria uma névoa espessa sobre os reais problemas da educação básica e relacionados a ela, nunca efetivamente enfrentados para a construção da nação.

Além disso, e não com menos importância, os problemas relacionados à vida cotidiana da maior parte dos estudantes de ensino médio, jovens de classes populares, afetam significativamente a trajetória escolar. Inseridos precária e precocemente no mundo do trabalho (como aprendizes ou mão de obra barata), sem as condições mínimas de complementar as poucas horas diárias de "instrução" oferecidas pelas instituições escolares, com pouco tempo de descanso, longos trajetos casa-escola-trabalho-casa, milhares de jovens pobres praticam uma espécie de corrida com obstáculos para frequentar a escola.

Esses mesmos jovens são submetidos a avaliações homogêneas, como se homogêneas fossem as condições de acesso, permanência e aprendizagens escolares.

Portanto, se a reforma parte de um diagnóstico parcial e ilusório, suas determinações encontrarão pouco eco na vida real das escolas e, pior do que isso, encaminhar-se-ão para encobrir faltas e problemas históricos, sob o discurso da flexibilização e da modernização.

Nessa mesma perspectiva situa-se a determinação de fazer escolas de ensino médio de tempo integral. Ampliar o tempo sob que condições? Ampliar o tempo com que objetivos?

Sem a perspectiva de formação humana integral, claramente explicitada na flexibilização curricular, que retira áreas importantes do currículo obrigatório, a mera ampliação do tempo não configurará a perspectiva de escolas de tempo e formação humana integral. Alongar a régua do tempo para ampliação da jornada escolar, sem redimensioná-la, não muda efetivamente os resultados do processo educativo, nem tampouco garante a permanência dos estudantes nos bancos escolares.

Em pleno século XXI, com experiências e reflexões pedagógicas mundo afora, apontando percursos escolares qualificados pela relação com os temas da cidadania, pela realização de experiências de médio e longo prazo de pesquisa, pela relação com circuitos de cinema, teatro, literatura, museus e poesia, pela incursão pelas novas mídias, 
pelas relações escola-comunidade, é inconcebível que se imagine fazer mais com menos recursos, menos formação de professores, menos escuta das comunidades educacionais.

Exemplifica isso a intenção deliberada da reforma quando retira a promoção do "desenvolvimento cultural dos estudantes" e a "Educação Física" da LDBEN. Mesmo que os movimentos posteriores de profissionais e de diferentes grupos tenham mudado essa proposição, a intencionalidade explicitada pode ser pensada nos seguintes termos: por que investir em desenvolvimento pleno - mesmo que assim esteja nominado na Constituição Federal - se muitos destes estudantes não serão sequer incorporados ao "mercado", se eles são os que sobrarão no rearranjo das forças produtivas tão ávidas de diminuir custos e ampliar ganhos?

Grave, também, na formulação da reforma é a total falta de referência às experiências de ensino médio que vem sendo desenvolvidas em diferentes estados e nas diferentes esferas da União. Não há nenhuma justificativa lúcida que possa sustentar, no campo da formação técnica e profissional, por exemplo, a proposição de itinerários de formação que não considerem o acúmulo nos mais de dez anos de construção da integração curricular e, até, na concomitância entre instituições de formação geral e formação profissional.

Inúmeras instituições educativas no Brasil vem construindo interessantes e diferenciados percursos formativos, que superam tanto as 800 horas/anuais mínimas previstas na LDBEN, quanto à abordagem disciplinar rígida, desequilibrada e fragmentada, configurando escolas de jornada ampliada, escolas normais, escolas integradas, escolas com alternância, escolas com concomitância. Não será um padrão único que responderá as demandas do ensino médio brasileiro.

O trabalho como eixo organizador do currículo, em conjunto com a tecnologia, a cultura e a ciência, apresentado nas Diretrizes Curriculares Nacionais para o Ensino Médio, em voga no País, construídas pelo Conselho Nacional de Educação, em diálogo com a sociedade brasileira e homologadas pelo Ministério da Educação em 2011, aponta para um caminho de integração e redesenho curricular, onde a dialogia entre as áreas de conhecimento e os saberes do mundo da vida produzam outros modos de percorrer níveis de conhecimento e experiências de vida qualificadores do ser e do estar no mundo.

Outro aspecto peculiar e preocupante diz respeito a inclusão da experiência de trabatho no setor produtivo como parte do tempo educativo e do currículo escolar. A rigor, as experiências de inserção dos jovens pobres em atividades produtivas não têm respondido a demandas formativas, pois, se assim fosse, todos os jovens, independentemente de classe social, deveriam ter essa inserção como parte de sua trajetória escolar. Corre-se o risco de que a referida inclusão diminua, ainda mais, o tempo de escola, pois, dificilmente, com a inexistência de uma intencionalidade na articulação da experiência de escola e trabalho, os saberes laborais comporão os projetos pedagógicos das escolas.

A propalada liberdade de escolha de itinerários formativos pelos estudantes em relação aos componentes não-obrigatórios do currículo materializar-se-á, de fato, em opções 
disponíveis, em face da falta de professores de determinadas áreas. Além disso, ignora a realidade de mais de $70 \%$ das cidades brasileiras, que têm apenas uma escola de ensino médio. Tal proposição poderá nos levar a gerações inteiras sem acesso aos conhecimentos da Física, da Química e da Biologia, que sofrem com a falta de professores e somente estarão presentes quando forem opções oferecidas como parte diversificada do currículo.

Outro elemento impactante da reforma é a retomada, a luz da Lei 5692/197, ordenamento educacional do Regime Militar, do Inglês como língua estrangeira obrigatória, em detrimento do caminho que vinha sendo percorrrido em direção à Língua Espanhola.

A questão do ensino de línguas no currículo escolar é bem mais ampla que a escolha de uma ou outra alternativa. Envolve aspectos relacionados ao projeto de desenvolvimento do País e seria desejável que se ampliasse o ensino de línguas estrangeiras nas escolas públicas, para múltiplas possibilidades e para além dos apertados períodos escolares de 45 ou 50 minutos, uma ou duas vezes por semana. Salas temáticas de línguas estrangeiras, bem como centros de ensino de línguas articulados às escolas de ensino fundamental e médio, com tempos estendidos, poderiam responder à demanda de modo efetivo. Trocar uma língua estrangeira por outra, no caso retornando ao Inglês, que nunca deixou de estar presente nas escolas públicas brasileiras, pelo expressivo número de professores formados na área, só reafirma o desprezo pelas relações Sul-Sul, que nos permitam maior entrosamento com os países da América Latina.

Esses são alguns aspectos da reforma proposta. Há outros. Pela longa experiência brasileira de reformar e não de construir ou reconstruir as bases do sistema educacional, sabemos do alcance limitado e limitador desse tipo de ação.

Reformar para retardar apresentar-se-á como o ancoradouro das mudanças que se podem colocar no caminho do ensino médio.

\section{As tarefas educativas em relação aos jovens}

A consciência de que o ensino médio brasileiro bebe na tradição livresca, intelectualista e elitista da educação brasileira e que sua função, mais do que explícita, é a de selecionar os jovens que avançarão para carreiras superiores e os muitos que ficarão de fora, aponta para a necessidade de repensar o ensino médio.

Os caminhos dessas mudanças respondem a diferentes projetos de sociedade. Grosso modo, apontamos uma perspectiva de manutenção dos lugares sociais que historicamente conhecemos que garante inserção e ascensão de acordo com berço e sobrenome, própria de sociedades desiguais e excludentes. Outra perspectiva é a de que é possível excluir essa régua e pensar uma sociedade que, pouco a pouco, através de políticas públicas continuadas e sistemáticas, garanta patamares de dignidade humana para a vida de todos e de cada um/cada uma. 
Reformar para retardar responde a primeira perspectiva, inscrita a ferro no imaginário de um país que se organizou a partir da desumanidade das relações entre escravos, feitores e senhores.

O que está em jogo é, nada menos, do que aquilo que desejamos como país e o projeto de futuro que estamos colocando em curso. Dito de outra forma, de que modo acolhemos e incluímos no nosso mundo comum os/as jovens, independentemente da origem social de cada um/cada uma.

Em jogo está a nosso papel de adultos de uma civilização que assume responsabilidades com o presente e o futuro de todos e de cada um. Nesse sentido, somos interpelados a nos perguntar como gerações adultas podem tornar facultativo aos jovens de um país inteiro conhecer ou não a história mundial ou os fundamentos da ciência moderna, que alavancaram o desenvolvimento tecnológico atual, ou saberes que permitam compreender o jogo de forças da economia mundial em relação à geografia dos países ou realizar experiências no campo da cultura, das artes, dos esportes e das tecnologias.

Não há dúvida acerca da necessidade de mudanças na estrutura pesada, vertical e fragmentada do ensino médio brasileiro. Porém, não é a retirada de determinados componentes curriculares, justo os que podem alargar a visão de mundo dos estudantes, que resolverá o problema. Novos desenhos curriculares, alicerçados em projetos de investigação e de inserção, acompanhados por professores de diferentes áreas, em diálogo, podem nos levar a outro patamar de oferta da educação básica, bem como a qualificação da infraestrutura e da carreira docente.

O caminho das mudanças do ensino médio, que estava em curso, apontava para a efetiva participação dos professores e equipes pedagógicas das escolas, sem os quais incorreremos em mudanças homogeneizadoras e distantes das demandas culturais, sociais e produtivas locais, que podem ser modificadas e qualificadas se a inserção dos jovens for respeitosa e diferenciada da que vivemos hoje. Aliás, nenhuma mudança na educação escolar pode ser levada a sério sem um efetivo projeto de formação inicial e continuada de professores e equipes gestoras das escolas.

O elemento definidor dos fins a que se destina o ensino médio, e, praticamente, toda educação básica, é a realização dos exames para acesso ao ensino superior. Mais do que todas as leis juntas, como disse certa vez Rubem Alves, esse condicionante define as trilhas de "instrução" no ensino médio, esvaziando a maior parte dos esforços na direção do pleno desenvolvimento da pessoa.

Há que se colocar no horizonte dos debates, no devir democrático que deverá ser retomado em breve no País, a ascensão ao ensino superior sem exames prévios, através de mecanismos que democratizem o acesso e qualifiquem as escolhas pelos jovens brasileiros. Tal perspectiva parece longínqua e inexequível, como certamente pareceu 
longínqua e inexequível a abolição da escravatura no Brasil para os humanistas da primeira metade do século XIX.

A seguir pelo caminho desenhado no ocaso do mais longevo intervalo democrático que o Brasil conheceu, daremos voltas sobre os temas propostos, fragilizaremos ainda mais as escolas e os professores, criaremos ilusões de "livres escolhas" e daqui a dez anos nos debruçaremos sobre os mesmos resultados de aprendizagem.

Aliás, seguir abordando a aprendizagem de determinados conteúdos escolares como o resultado esperado de todo trabalho do sistema escolar, independentizando-o dos processos mais amplos de desenvolvimento cognitivo, emocional, ético, cidadão, estético, entre outros aspectos, é um modo de manter uma névoa densa em relação aos problemas estruturais da educação brasileira.

As avaliações de larga escala, baseadas na premissa de algumas aprendizagens específicas, representam, também, no atual cenário mundial, uma clara adequação a imperativos de realinhamento colonizatório que nos mantém distantes de nossas demandas e necessidades.

Avaliar, sim, mas abordar globalmente o desenvolvimento dos estudantes, incluindo a análise das condições nas quais os processos de desenvolvimento são efetivados no cotidiano das escolas. Fora disso, seguiremos tergiversando e legitimando uma visão amplamente alimentada por interesses de variadas ordens para a qual as escolas públicas são, no seu conjunto e por sua própria culpa, improdutivas e desqualificadas.

Urge retomarmos a normalidade democrática e o sentido de um projeto nacional de educação pública, baseado nas metas e estratégias previstas no PNE 2014-2024, nos debates desencadeados pelas conferências municipais, regionais, estaduais e nacional de educação, bem como na efetiva participação dos professores e comunidades escolares na construção da imprescindível autonomia, que denomino como maioridade institucional das escolas de educação básica, tão maltratadas pelos arranjos partidários e descontinuidades administrativas, que consomem esperanças e vontades individuais e coletivas.

Encerro com palavras de Anísio Teixeira (1957), que sonhou uma educação pública e de qualidade para todos. Ele insistia que nos estamos a repetir na história do Brasil e nos lembra a extensão da nossa tarefa:

Nada é mais capaz que o sonho que a inteligência humana...se o grande poder criador da humanidade, o poder que nos dá o sentido e a interpretação da própria vida não é cultivado, nem estimulado, não virá a secar-se a sua fonte inspiradora e com ela desaparecer a qualidade humana da civilização?

Recebido em 22/06/2017 e aprovado em 25/06/2017 


\section{Referências}

ARENDT, H. A Condição Humana. Tradução de Roberto Raposo; revisão técnica: Adriano Correia. $8^{a}$ ed. Rio de Janeiro: Forense Universitária, 2010.

Conselho Nacional de Educação. Câmara de Educação Básica. Diretrizes Curriculares Nacionais para o Ensino Médio. Brasília, 2011.

LECLERC, G.; MOLL, J. Educação integral em jornada diária ampliada: universalidade e obrigatoriedade? Revista Em Aberto. INEP, Brasília, v. 25, n.88, p. 17-49, 2012.

MOLL, J. (organizadora) Caminhos da educação integral no Brasil: direito a outros tempos e espaços educativos. Porto Alegre: Artmed, 2012.

MOLL, J. Alfabetização possível: reinventando o ensinar e o aprender. 5. Ed. Porto Alegre: Mediações, 2001.

MOLL, J. Histórias de Vida, histórias de escola: elementos para uma pedagogia da cidade.

Petrópolis: Vozes, 2000.

PATTO, M. H. S. A produção do fracasso escolar: histórias de submissão e rebeldia. São Paulo: T.A. Queiroz, 1990.

KERSTENEETZKY, C. L. Escola em tempo integral já: quando quantidade é qualidade. In: Ciência hoje. v. 39, n. 231, p. 18-23, out. 2006.

RIBEIRO, D. Nossa escola é uma calamidade. Rio de Janeiro: Salamandra, 1984.

TEIXEIRA, A. S. Educação não é privilégio. Rio de Janeiro: José Olímpio, 1957.

TEIXEIRA, A. S. Educação no Brasil. Rio de Janeiro: UFRJ, 2011. 